\title{
Grupos de interés, valores y significados del sitio arqueológico Intihuasi, provincia de San Luis, Argentina. Un análisis orientado a su gestión patrimonial
}

\author{
M. Luz Endere \\ (iD) https://orcid.org/ 0000-0001-8500-2512 \\ Patrimonia, Investigaciones Arqueológicas y Paleontológicas del Cuaternario Pampeano (INCUAPA), Facultad de \\ Ciencias Sociales, Universidad Nacional del Centro de la Provincia de Buenos Aires (UNICEN) y Consejo Nacional \\ de Investigaciones Científicas y Técnicas (CONICET). Av. Del Valle 5737 (CP B7400NJK), Olavarría, Buenos Aires, \\ Argentina. E-mail: mendere@soc.unicen.edu.ar
}

\section{Gabriela Chaparro}

(D) https://orcid.org/0000-0003-3785-2912

Patrimonia, Investigaciones Arqueológicas y Paleontológicas del Cuaternario Pampeano (INCUAPA), Facultad de Ciencias Sociales, Universidad Nacional del Centro de la Provincia de Buenos Aires (UNICEN) y Consejo Nacional de Investigaciones Científicas y Técnicas (CONICET). Av. Del Valle 5737 (CP B7400NJK), Olavarría, Buenos Aires, Argentina. E-mail: chaparro@soc.unicen.edu.ar

\section{Vanesa Giacomasso}

\section{(iD) https://orcid.org/0000-0003-1754-877X}

Patrimonia, Investigaciones Arqueológicas y Paleontológicas del Cuaternario Pampeano (INCUAPA), Facultad de Ciencias Sociales, Universidad Nacional del Centro de la Provincia de Buenos Aires (UNICEN) y Consejo Nacional de Investigaciones Científicas y Técnicas (CONICET). Av. Del Valle 5737 (CP B7400NJK), Olavarría, Buenos Aires, Argentina. E-mail: vanegiaco05@gmail.com

\begin{abstract}
Resumen
El sitio arqueológico Intihuasi ha marcado un hito en la arqueología argentina a mediados del siglo XX. Pese a estar legalmente protegido y gestionado por la provincia, que ha construido en las últimas décadas infraestructura turística con personal permanente afectado a su protección, ha perdido atractivo debido a la acumulación de impactos antrópicos y naturales. Recientes investigaciones en el área y el empleo de nuevas tecnologías permitieron la identificación de nuevas pinturas y aportaron información inédita que reactivarán su valoración científica. El gobierno provincial está interesado en poner en valor a Intihuasi y constituirlo en un punto de referencia del turismo cultural regional, razón por la cual patrocinó nuevas investigaciones y la elaboración de un plan de manejo. En este trabajo se presenta parte de los resultados obtenidos, vinculados con el estudio de su significación cultural; para ello se identificaron los grupos de interés involucrados, se relevaron y evaluaron los valores atribuidos al sitio. Así mismo se reconstruyó la historia del lugar, las diferentes etapas de su gestión, su situación jurídica y condiciones de conservación. A partir de esta información se espera contribuir al diseño de una gestión patrimonial orientada a valores para Intihuasi.
\end{abstract}




\title{
Stakeholders, values, and meanings of the Intihuasi archaeological site, San Luis Province, Argentina. An analysis oriented to its heritage management
}

\begin{abstract}
The Intihuasi archaeological site has established a milestone in Argentine archeology in the mid-twentieth century. Despite being legally protected and managed by the province that has built, in recent decades, tourism infrastructure with permanent personnel involved in its protection, the site has lost its attraction due to the accumulation of anthropic and natural impact. Recent research in the area and the use of new technologies allowed the identification of new paintings and provided unpublished information that will revive its scientific value. The provincial government's interest in enhancing Intihuasi to turn it into a reference point for regional cultural tourism led to sponsoring new research and the development of a management plan. In this paper, we present part of the results, linked to the assessment of the cultural significance of the site. We identified the stakeholders involved, and we surveyed and evaluated the values attributed to the site. We also reconstructed the history of the place, the different stages of its management, its legal situation, and preservation conditions. Based on this information, we expect to contribute to the design of value-oriented management for Intihuasi.
\end{abstract}

KEYWORDS: Archaeological heritage; Cultural significance assessment; Value oriented management; Stakeholders; Conservation.

\section{Introducción}

La Gruta de Intihuasi está localizada en el departamento de Coronel Pringles, en el sector septentrional de la provincia de San Luis. Se trata de una cueva con una superficie superior a los $800 \mathrm{~m}^{2}$, ubicada en el frente oriental del cerro homónimo, cuya boca principal mira al sureste. Su nombre deriva de la voz quechua que significa "casa del sol". Se destaca por ser el sitio donde el arqueólogo Alberto Rex González realizó el primer fechado radiocarbónico (González, 1960).

Desde hace dos décadas Intihuasi se encuentra abierto al público. En el año 2019 el gobierno de la provincia de San Luis nos encargó, junto a un equipo mayor de investigadores, principalmente geólogos y arqueólogos de la Universidad de San Luis, la realización de nuevos estudios que incluyeron la evaluación sobre la gestión patrimonial del sitio. Esta investigación constó del análisis del marco legal (Giacomasso y Endere, 2019), una evaluación del estado de conservación de la gruta, la identificación de grupos de interés, la declaración de la significación cultural del sitio y la elaboración de lineamientos para un plan de manejo (Endere, Chaparro y Giacomasso, 2019). Cabe destacar que en el presente trabajo se hace foco en uno de dichos aspectos: el que refiere a las valoraciones de los grupos de interés implicados.

Se señala que, en relación a la gestión patrimonial a nivel internacional, se han aplicado dos enfoques principales: uno que se puede denominar convencional $\mathrm{y}$, el otro, orientado a valores. Ambos coexisten en la práctica y no son excluyentes, aunque este último es el que se impone por ser más inclusivo y respetuoso de la diversidad cultural. La metodología convencional está vinculada a la posguerra, donde el propósito principal del manejo de los recursos culturales era la conservación de los materiales y los criterios para esa tarea eran exclusivamente definidos por los expertos (ICOMOS, 1964). En cambio, el enfoque orientado a valores evalúa la significancia de un bien o manifestación cultural, de acuerdo a las valoraciones de todos los agentes involucrados y mediante estrategias de participación comunitaria (UNESCO, 2013). Con esa base 
se formula una declaración de significación para la implementación de lineamientos y procedimientos de gestión y conservación que consideren no sólo al bien, sino principalmente a los grupos y las comunidades implicadas. Hay que tener en cuenta que las valoraciones son dinámicas e incluyen diversidad de opiniones y conflictos potenciales y/o reales que deben ser considerados para la toma de decisiones. Este enfoque es ampliamente utilizado como política de gestión en diversos países como Canadá, Estados Unidos, Australia, Gran Bretaña y ha sido recomendado por organismos internacionales (ver UNESCO, 2013).

A partir de lo mencionado, en el presente trabajo se describe y analiza la manera en que se han identificado los grupos de interés implicados en el proceso de valoración de Intihuasi y se desarrolla el análisis de la significación cultural del mismo. Ambos estudios son primordiales para llevar adelante una gestión patrimonial orientada a valores, acordes a las llamadas buenas prácticas del patrimonio cultural (Endere et al., 2018). En la primera parte del artículo se desarrolla una breve historia de las investigaciones del sitio y se detallan las diferentes acciones que se llevaron a cabo a lo largo del tiempo para mejorar el acceso público a Intihuasi y su condición jurídica. Posteriormente, se desarrollan los estudios sobre los visitantes al sitio, los usos y las condiciones de conservación del mismo. Luego se relevan e identifican los valores involucrados a fin de evaluar la significación social y cultural de los diferentes grupos de interés, lo que incluye la identificación de conflictos reales o potenciales. La declaración de la significación cultural se realiza mediante el análisis de los valores en juego y el grado de importancia asignados por cada uno de ellos (Avrami, Mason y De La Torre, 2000; Feilden y Jokilehto, 1993; Lipe, 1990). La metodología implementada se sustenta en un abordaje cualitativo basado en la realización de entrevistas y encuestas a partir de las cuales se identifican los propios saberes de los protagonistas en su contexto social y cultural, dentro de su marco de referencia (Taylor y Bogdan, 1996).

\section{Intihuasi y su devenir histórico}

\section{Investigaciones arqueológicas en Intihuasi}

Desde el siglo XIX hay publicaciones que mencionan el potencial arqueológico de Intihuasi. Heider y Curtoni (2016) son los arqueólogos que han profundizado en la indagación de los antecedentes de estudio en la cueva. Según estas investigaciones, el primer trabajo fue el de German Avé-Lallemant ${ }^{1}$ (1875), quien identificó la ocupación humana indígena e indicó realizar excavaciones arqueológicas y geológicas en la misma. Ambos, con Germán Conrado Burmeister ${ }^{2}$, las planificaron pero no las pudieron concretar por razones de financiamiento. Este último es el que asignó la ocupación de Intihuasi a una antigüedad reciente (Burmeister, 1876; Heider y Curtoni, 2016). Posteriormente Florentino Ameghino realizó la descripción de unos artefactos recuperados en la cueva, les designó una cronología "de antiguos o modernos" según fueran observados como toscos o mejor trabajados e hizo referencia a las pinturas rupestres del sitio (Ameghino, 1885; Fernández, 1982; González, 1960). Según los

1 Ingeniero alemán, realizó expediciones topográficas y de agrimensura en San Luis y exploraciones mineras en los yacimientos de oro de La Carolina. En 1872 fue designado rector interino del Colegio Nacional de San Luis. Autor de la obra "Memoria descriptiva de la provincia de San Luis". Fue integrante de varias sociedades científicas de la época (Ferrari, 1993; Heider y Curtoni, 2016).

2 Nació en Alemania y al nacionalizarse argentino cambió su nombre por Burmeister. Fue discípulo de Humboldt y llegó a la Argentina durante la presidencia de Bartolomé Mitre con el cargo de Director General del Museo Público de Buenos Aires. Fue impulsor de la Academia de Ciencias de Córdoba (1869). Se casó con una mujer de apellido Lucero, nacida en La Carolina, por lo que visitaba asiduamente San Luis (Curtoni y Heider, 2019). 
estudios posteriores, no queda claro si las referencias de Ameghino son efectivamente de Intihuasi y no hay registros de que haya visitado la cueva (Curtoni y Heider, 2019).

En cuanto a los estudios realizados por investigadores locales en el siglo XX se destaca la "Historia de la Provincia de San Luis" (Gez, 1916), donde se afirma que un grupo diaguita denominado "Michilingües" ingresaron al territorio puntano en momentos de la expansión inca, proceso que explica la cantidad de topónimos en quechua que persisten en la región. Félix Outes (1926) también abordó el estudio de Intihuasi principalmente al realizar observaciones acerca de las divergencias en cuanto a la ubicación de las representaciones rupestres, así como a la descripción de materiales arqueológicos. Posteriormente Francisco De Aparicio visitó Intihuasi (De Aparicio, 1926-1928, p. 457), recogió material arqueológico y describió el uso turístico que ya tenía la cueva para ese entonces. Además, señaló que las pinturas rupestres de la misma se encontraban con grandes problemas de conservación. Paralelamente, el arquitecto Héctor Greslebin (1928) realizó una excursión arqueológica a la cueva sin agregar muchos más datos que los anteriores. A diferencia de estas visitas, Milcíades Vignati $(1936,1937,1941)$ realizó estudios durante más de diez años en San Luis y en particular en Intihuasi. Vignati, en ese entonces Jefe de la División de Antropología del Museo de La Plata, realizó las primeras excavaciones en la cueva y estudió el arte rupestre. Señaló, al igual que De Aparicio, el deterioro que ya poseían las pinturas, especialmente por la acción de los visitantes que las grafitaban y decidió "lavar" las paredes de la cueva.

Una década después, las excavaciones del Dr. Alberto Rex González de 1951 en Intihuasi marcaron un momento clave en la historia de la arqueología argentina, por la importancia de la interpretación de los contextos y por las técnicas implementadas (González, 1960; Heider y Curtoni, 2016). El contacto del gobierno provincial con este prestigioso arqueólogo se produjo debido a que tres años antes de su llegada habían quedado expuestos gran cantidad de objetos arqueológicos y sedimentos, producto de la construcción de un camino de acceso hasta la gruta por parte de Vialidad provincial. Los fechados realizados sobre los huesos quemados de la excavación (niveles 3-4) arrojaron como resultados $7970 \pm 100$ años y $8068 \pm 95$ años $^{3}$ (González, 1960, p. 158), constituyéndose en las primeras dataciones radiocarbónicas del país. Los mismos le permitieron a Rex González confeccionar una secuencia de ocupación para los grupos humanos de Sierras Centrales (González, 1960).

Luego de los trabajos de González y recién varias décadas después, Mario Consens efectuó un análisis sistemático de las expresiones rupestres de la región utilizando fotografía infrarroja (Consens, 1986). Su relevamiento intensivo y la utilización de esta nueva tecnología le permitieron definir cinco estilos con una distribución geográfica específica, uno de los cuales fue el estilo Inti Huasi, caracterizado por motivos geométricos en rojo oscuro, en rojo violáceo y en negro.

Los recientes estudios realizados en Intihuasi (Curtoni et al., 2019) han permitido obtener un nuevo fechado radiocarbónico que indica que las primeras ocupaciones de la región son más antiguas de lo que se suponía. Estos autores proponen, de manera preliminar y hasta tanto se analicen nuevos materiales expandiendo la excavación, que la ocupación permanente de San Luis por parte de los pueblos originarios se inició en el Holoceno temprano y no a principios del Holoceno medio, como se suponía hasta el momento. Actualmente el fondo de la cueva está cubierto de vegetación que no permite visualizar el arte; no obstante, los nuevos estudios vuelven a posicionar a Intihuasi como un yacimiento con alto valor para recuperar evidencias sobre los primeros pobladores de San Luis en particular y del centro de Argentina, en general.

3 Los laboratorios fueron Yale Natural Radiocarbon Measurements III y la Universidad de Pensilvania respectivamente (González, 1960). 


\section{La gestión de Intihuasi como sitio patrimonial}

Las tierras donde se localiza el Cerro de Intihuasi pertenecían desde 1787, por merced real, a Esteban Fernández y Fernando Lucero (Cabrera, 1929, p. 278). La propiedad continuó en manos de la familia Lucero y la gruta tuvo un intenso uso social como se verá más adelante. A partir de su identificación como sitio arqueológico en la segunda mitad del siglo XX, la cueva fue objeto de diversas acciones para su apertura al público, que generaron diferentes impactos sobre la misma. En 1978, una superficie de dos hectáreas que incluye el sitio pasó a ser propiedad de la provincia de San Luis. Con posterioridad la gruta continuó en custodia de los Lucero y en 1982 Vialidad hizo el cementado de $100 \mathrm{~m}$ hasta su entrada en la línea de goteo.

En el 2003 la provincia construyó la confitería y la casa de los cuidadores. En el 2004 se sancionó la Ley de Yacimientos Paleontológicos y Arqueológicos N II-0062-2004 (5.740) que declara de interés científico a los sitios arqueológicos con arte rupestre de la provincia, entre los cuales se incluye a Intihuasi. Como consecuencia de ello, en 2008 se iniciaron obras de puesta en valor, en paralelo con las políticas provinciales de reconocimiento de las culturas originarias. En ese marco se destaca la sanción de la Ley provincial No V-0600-07 que reconoce "la preexistencia étnica y cultural de todas las comunidades originarias del territorio", establece "la restitución de las tierras que históricamente les han pertenecido" (art. 2) y señala la importancia de reconocer "sus derechos a determinar libremente su futuro como pueblo" y garantizar "el respeto irrestricto de su identidad autóctona".

Las obras del año 2008 incluyeron la ampliación de la casa y la confitería con la construcción de nuevos baños y un salón superior. Asimismo, se construyó un centro de interpretación con paneles que brindaban información arqueológica e histórica del sitio $^{4}$, en un gran contenedor de madera ubicado en el acceso, el cual visualmente cerraba la entrada de la gruta. Posteriormente se quitó esa construcción de madera, quedando las bases a la vista. En la misma época se hicieron los portones y las pasarelas, que se conservan hasta la actualidad.

En 2010 se implementaron, desde el gobierno provincial, corredores turísticos. Algunos de ellos, como el Comechingón, el del Centro y el de Las Serranías, llegaban hasta La Carolina y ponían a Intihuasi como un anexo. Luego se generó el circuito Culturas Originarias con dos variantes: Comechingones y el Centro. En ese marco, la gruta quedaba comprendida en el circuito de Paso del Rey - La Angostura - Intihuasi - Casa de Piedra Pintada. La principal dificultad de estos circuitos es que había tramos no asfaltados, algunos muy complicados, por lo que la iniciativa no prosperó.

El sitio, en su presente condición jurídica, depende de la Jefatura de Área Museo de La Poesía "Juan Crisóstomo Lafinur", ubicado en la localidad de La Carolina. Este museo es de gestión provincial, con presupuesto afectado y dependiente del organigrama del Programa Cultura de la Secretaría General de Gobernación de San Luis.

En la actualidad, a la entrada de la gruta se encuentran una arcada de acceso y la confitería, lugar que funciona como centro de visitantes. Para acceder al sitio propiamente dicho se debe ascender por un camino de asfalto (realizado por Vialidad Provincial en 1982) y, en la entrada de la cueva, se encuentran pasarelas para no

4 Estos paneles presentaban información sobre las investigaciones realizadas por Rex González que incluía un panorama general y comparativo del poblamiento humano, la secuencia ocupacional de la cueva con imágenes de las excavaciones de esa época y reproducciones de los diseños del arte rupestre. Ya hace un par de años que estos paneles fueron retirados, estaban muy deteriorados y los textos alterados por el impacto de la luz solar directa. 
pisotear el sedimento que posee una trama de cuadrículas de metal simulando una excavación arqueológica. A lo largo del trayecto hay algunas vitrinas con materiales arqueológicos expuestos, que fueron cedidos en préstamo por la familia Asburger ${ }^{5}$ (Figuras 1, 2 y 3). El personal afectado al sitio es de 12 personas, seis de ellas ocupadas del mantenimiento, cuatro de la información turística y dos cuidadores que residen en la entrada y atienden la confitería. Durante los fines de semana se suma un guía especializado con una larga trayectoria de trabajo en la zona.

En los alrededores de Intihuasi, considerando Cerro Largo y Cañada Honda, viven unas 200 personas de manera dispersa, dedicadas principalmente a la actividad agropecuaria, complementada con los planes de asistencia social del gobierno. La zona

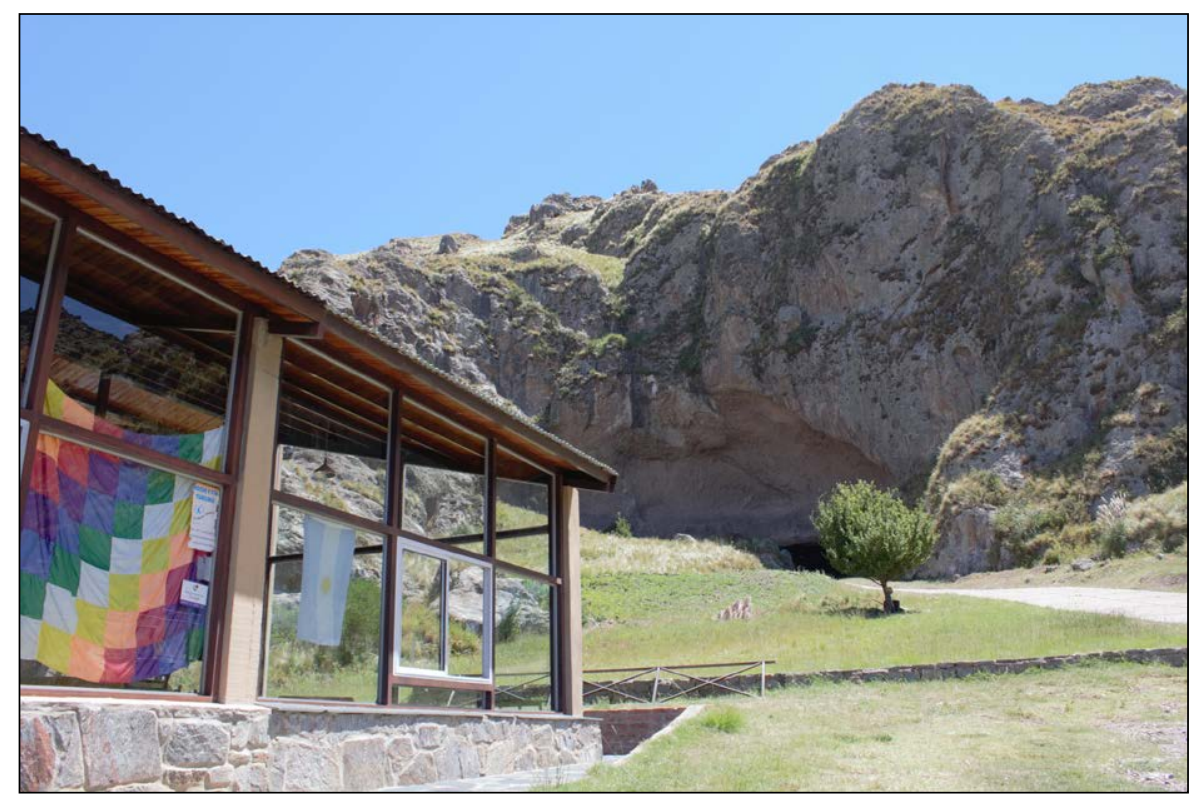

Figura 1. Vista de la confitería y de fondo la gruta Intihuasi.

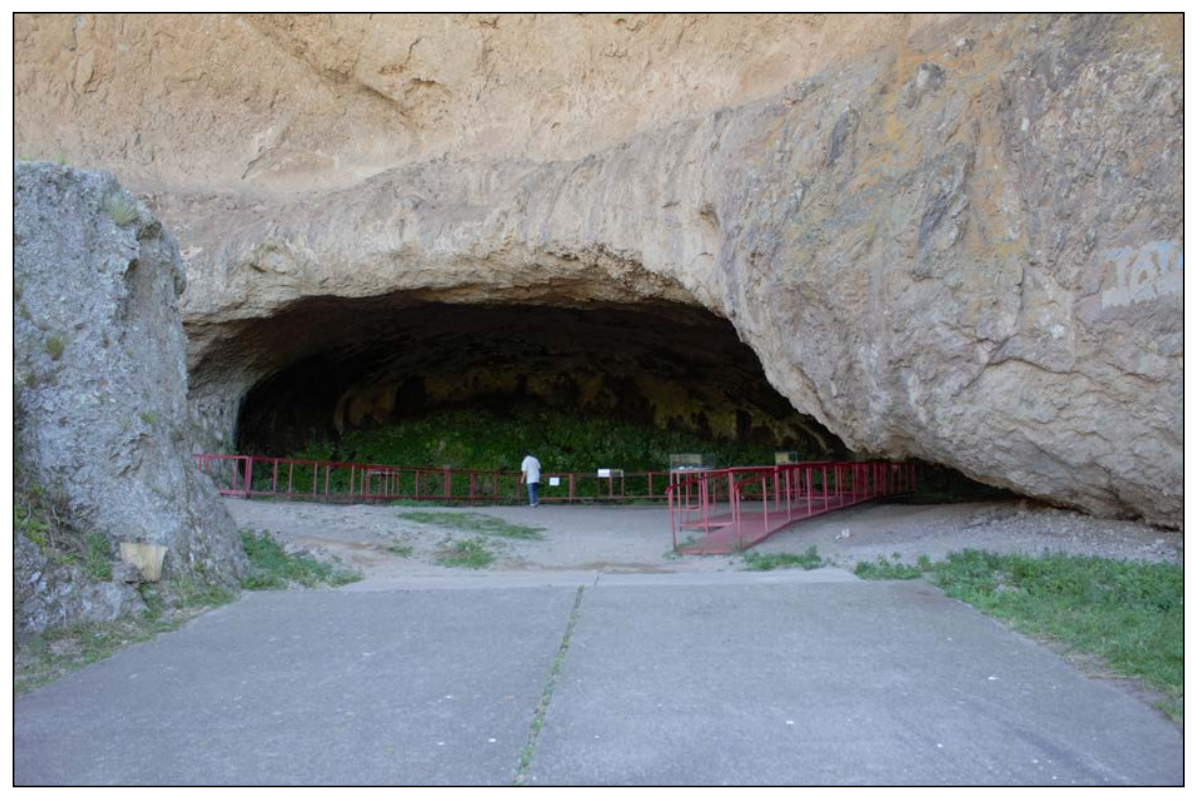

Figura 2. Vista del pavimento colocado hasta el ingreso de la cueva.

5 Algunos de estos artefactos fueron hallados en superficie por uno de los impulsores de la construcción de las pasarelas en el 2008. 


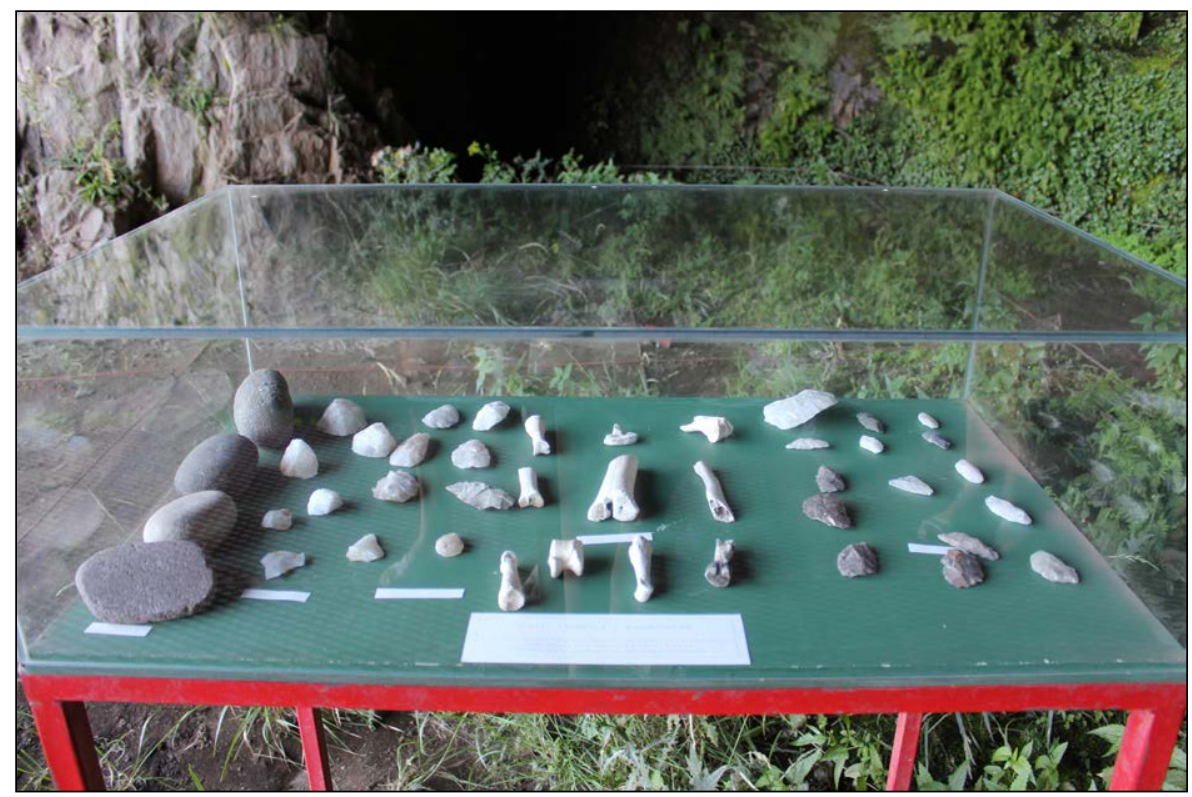

Figura 3. Materiales arqueológicos exhibidos dentro de la gruta.

cuenta con una escuela primaria donde se centralizan las actividades comunitarias y religiosas. La familia Lucero es una referencia significativa en la comunidad por su permanencia y por tener la propiedad de las tierras aledañas al sitio.

El núcleo urbano más cercano a la gruta de Intihuasi es La Carolina, ubicada a unos 20 km de distancia y reúne unos 251 habitantes $^{6}$, según el censo de población 2010. Se trata de un poblado de origen colonial, creado por disposición del Marqués de Sobremonte en 1792 y su nombre fue elegido como homenaje al Rey Carlos III. EI interés de los españoles en la zona se debió a la existencia de yacimientos de oro, los cuales fueron descubiertos en 1785 en los flancos del cerro Tomolasta y en Cañada Honda (Funes, 2006; Montes, 1955; Pérez Gutiérrez de Sánchez Vacca, 1998; Tobares, 1996; Vacca y Núñez, 1967). La explotación del oro es una cuestión que atraviesa la historia de La Carolina y de sus pobladores, ya que muchos de ellos son descendientes de mineros, con varias generaciones viviendo en la zona. Los restos materiales de esta actividad constituyen actualmente un recurso para el turismo cultural, haciéndose hincapié en la importancia de mantener la identidad de La Carolina como pueblo minero (Funes, 2006). Si bien la principal actividad económica es la agropecuaria, como la cría de animales y la plantación de papa, todavía se practica la minería artesanal mediante el lavado de oro. A esto se suma que alrededor del $85 \%$ de los pobladores son beneficiarios de planes sociales aunque, en las últimas décadas, se ha hecho una apuesta fuerte al turismo cultural a partir de iniciativas públicas y privadas.

\section{Aproximaciones metodológicas para una gestión patrimonial orientada a valores}

Caracterizar o seleccionar un objeto o una manifestación cultural es la primera medida para su protección, lo que permite agrupar la mayor cantidad de aspectos posibles para comprenderlo y a la vez valorarlo, en función de los significados que el mismo tiene asignado. A la hora de la gestión patrimonial es importante identificar los valores que los grupos o las personas les asignan, teniendo en consideración el marco social,

6 Ver información disponible sobre la cantidad de población por departamento y localidades en: https:// www.citypopulation.de/php/argentina-sanluis_s.php 
cultural y psicológico de referencia. Esto no siempre fue de esta manera, ya que desde mediados del siglo XX para los sitios y yacimientos arqueológicos -al igual que para la mayoría de los bienes - sólo fue considerado el criterio de los llamados especialistas. Aún hoy es habitual cierto predominio del valor científico ligado exclusivamente a la autenticidad, el cual fue establecido por la Carta de Venecia (ICOMOS, 1964), colocando el aspecto material o físico como prioridad. La prevalencia de este criterio técnico/ científico ya hace más de cuatro décadas fue cuestionado a nivel internacional. La Carta de Burra (ICOMOS, 1979) y el Documento de Nara (Larsen, 1995) fueron claves para reconsiderar los juicios de valor del patrimonio cultural e incluir los de los grupos de interés, no sólo la valoración de los expertos. Adoptar el enfoque de gestión basado en valores es, en muchos sentidos, una respuesta al reconocimiento de la creciente complejidad del patrimonio (Endere y Prado, 2009; Grenville y Fairclough, 2004; Lipe, 1990). Este enfoque se inspira en la Carta de Burra que define a la "significación cultural" como el valor estético, histórico, científico, social o espiritual que un bien posee para las generaciones pasadas, presentes y futuras. Se corporiza en el sitio propiamente dicho, en su estructura, entorno, uso, asociaciones, significados, registros, sitios y objetos relacionados. Cada objeto o manifestación cultural puede tener un rango de valores para diferentes individuos o grupos, de modo que la identificación de estos valores es crucial para determinar la evaluación de significación cultural y, en base a ella, establecer las políticas y estrategias de protección, conservación y gestión que tengan en cuenta esas valoraciones (De la Torre, 2002; UNESCO, 2013).

En este marco, con el objetivo de relevar y analizar opiniones, usos y apropiación se efectuaron entrevistas semi-estructuradas a la población local y diversos grupos de interés (funcionarios públicos, docentes, guías, encargados del sitio, promotores de turismo, etc.). Estas incluyeron preguntas abiertas y cerradas que fueron realizadas en San Luis, La Carolina e Intihuasi. Asimismo, para indagar al público visitante a la gruta, se utilizaron técnicas encuadradas en lo que se denominan estudios de público (García Blanco, 1999; Pérez Santos, 2000) con el propósito de conocer el perfil de los visitantes y el grado de satisfacción de los mismos. En este caso, se emplearon encuestas semi-estructuradas (preguntas cerradas múltiple choice y otras abiertas) que se realizaron al azar cuando se estaba realizando la excavación arqueológica. También se analizó el libro de visitantes, ya que en él se dejan mensajes y sugerencias que pueden ser de utilidad.

\section{Usos de la gruta y estado de conservación}

El sitio ha estado expuesto a una serie de impactos naturales y antrópicos que afectaron y siguen afectando su preservación. Al respecto, diversos testimonios que fueron extraídos de las entrevistas señalan su uso como corral para animales y espacio de congregación de los habitantes de la comarca para realizar diferentes tipos de festejos (i.e. religiosas, patrias, bailes, carreras cuadreras) y, principalmente en la década de los noventa, la gruta fue elegida como destino de viaje para recreación durante el día por parte de los habitantes de la capital provincial. Fabián Romero, que en ese entonces comenzó a trabajar como guía freelance, identificó que la gente que la visitaba entraba con el automóvil, dejaba basura, rayaba y pintaba la cueva. Él afirma haber construido una pirca, que luego se desmoronó, para evitar que la gente ingresara con vehículos a la gruta.

Además de los usos mencionados, hay que señalar los impactos de notoria importancia que generaron la remoción de tierra realizada por la Dirección Provincial de Vialidad y la posterior excavación extensiva en una amplia superficie efectuada por el Dr. Alberto Rex González en 1960. Por otra parte, con los años se realizaron sucesivas construcciones en el marco de la puesta en valor del sitio, que también afectaron la 
integridad de Intihuasi. Pueden mencionarse entre otras: el ensanchamiento de la entrada, el camino pavimentado, la construcción de muros y cimientos, la colocación de pasarelas (Figura 4) y la construcción de infraestructura turística accesoria (i.e. casa, confitería, ampliación posterior, cercados).

No menos significativo es el impacto de origen natural debido a que el cerro Intihuasi tiene una serie de fallas y grietas naturales generada por sucesivos movimientos

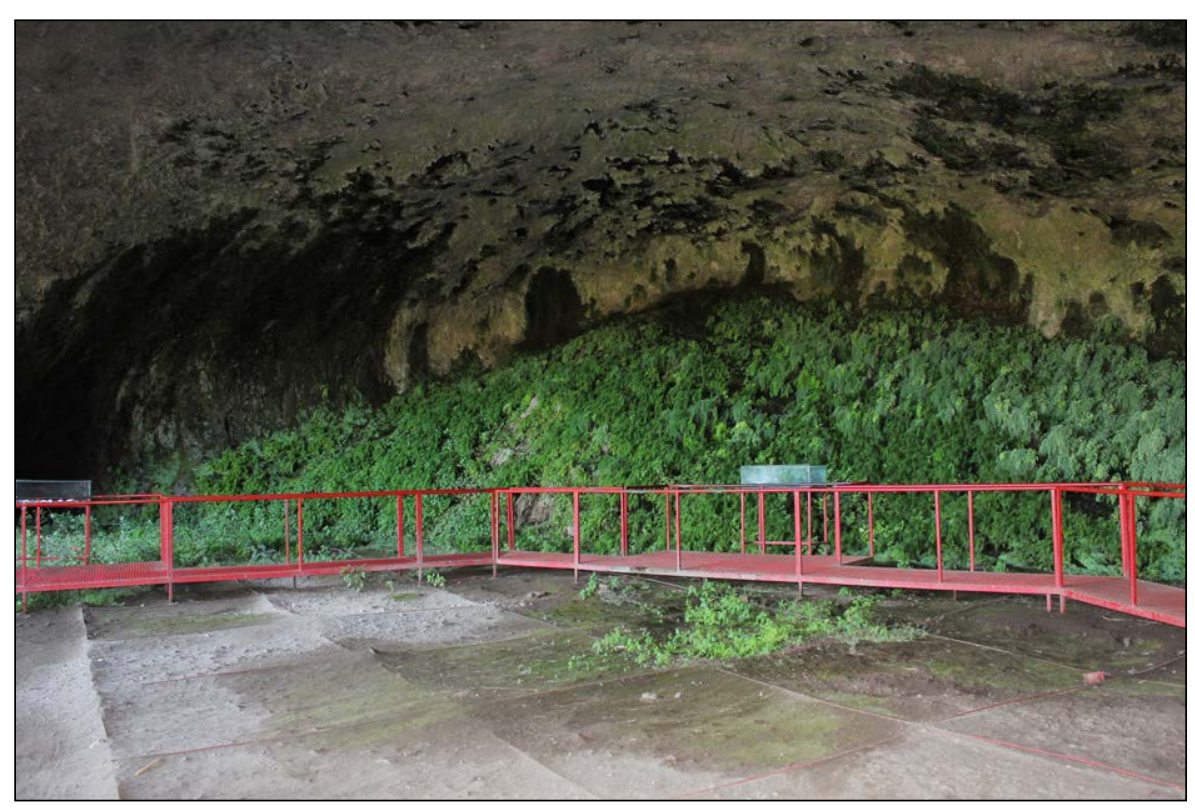

Figura 4. Vista de las pasarelas, de las cuadrículas y, al fondo, de la cubierta vegetal que recubre la cueva.

sísmicos, principalmente el ocurrido a finales de la década de 1970. Estas fracturas han ocasionado importantes filtraciones de agua en el interior de la cueva, que generan zonas encharcadas y de constante humedad que han hecho proliferar una cubierta vegetal importante de musgos y helechos que es permanente (ver Figura 4). Esto, sumado a las condiciones de temperatura y humedad, han ocasionado un daño irreparable a las pinturas rupestres, hoy imperceptibles al ojo humano.

\section{Los visitantes y la actividad turística}

La gruta está abierta al público los siete días de la semana, en el horario de 9 a 19 horas y la entrada es libre y gratuita. Actualmente se ingresa a ella siempre acompañado por un guía. La visita es ofrecida por las oficinas de turismo provinciales a la entrada al pueblo de La Carolina y en el Complejo Lafinur. También la ofrecen guías independientes y agencias de turismo de La Carolina ${ }^{7}$, San Luis y Merlo. Por otro lado, en las proximidades de la entrada al predio se emplaza la vivienda y hostería de la familia de Julio César Lucero que ofrece alojamiento y comida para quienes quieran pernoctar.

En el marco del proyecto mencionado se realizaron estudios de público con el fin de conocer cuestiones vinculadas al perfil de los visitantes, su procedencia, sus

7 Por ejemplo "Huellas Turismo" trabaja de manera articulada, ofreciendo actividades de turismo educativo tales como visitas guiadas y un taller de sobado de cueros, pinturas, etc., que se ofrecen en el local de la confitería. 
intereses, percepciones y opiniones. Para ello se entrevistaron a los guías del sitio y de La Carolina, se realizaron encuestas a los visitantes y se analizó el libro de visitas que se encuentra en la confitería de acceso. De acuerdo con los resultados que más abajo se desarrollan, se puede concluir que las épocas de visita son principalmente en verano (entre enero y marzo), Semana Santa y fines de semana largos. La mayor parte de los visitantes procede de las provincias de San Luis y Buenos Aires y acceden por cuenta propia en sus automóviles. Es significativa la baja presencia de contingentes.

Las encuestas se hicieron a todos los visitantes que asistieron al sitio $(\mathrm{N}=32)$ durante cinco días, del 9 al 13 de junio de 2019 (temporada baja), mientras se realizaba la excavación arqueológica. La mayor parte de los turistas eran procedentes de la provincia de Buenos Aires $(n=27)$, con una representación mínima de otros lugares, como San Luis $(n=4)$ o Entre Ríos $(n=1)$. El objetivo de la visita fue principalmente de excursión educativa $(n=19)$ y el resto $(n=13)$ para la recreación/paseo. La gran mayoría $(n=29)$ dio una opinión favorable acerca de la visita. Los adjetivos que se destacaron fueron: muy interesante, muy buena, agradable, hermosa, genial, atractiva, excelente. Sólo tres no contestaron.

Al preguntar sobre lo que más le gustó de la visita, los visitantes hicieron referencia a dos aspectos: por un lado, mencionaron las explicaciones de los guías, ya que las mismas fueron importantes para entender de qué se trataba el sitio. Por otro, destacaron el paisaje del lugar (Tabla 1). En cuanto a lo que menos les agradó, las respuestas hicieron foco en la presencia de elementos que obstaculizan la apreciación de la gruta (e.g. el pavimento, las pasarelas, el muro, etc.) y reclamaron mayor información acerca del sitio (Tabla 1).

\begin{tabular}{|c|c|c|}
\hline \multicolumn{3}{|c|}{$\begin{array}{l}\text { Opiniones acerca de la visita a Intihuasi (visitantes } \mathbf{N}=32 \text { ) } \\
\text { Múltiples respuestas }\end{array}$} \\
\hline & ¿Qué le gustó más? & ¿Qué es lo que menos le gustó? \\
\hline $\begin{array}{l}\text { Accesibilidad física y } \\
\text { visual }\end{array}$ & Paisaje/Lugar: 14 & $\begin{array}{l}\text { Subida empinada: } 2 \\
\text { Presencia de asfalto: } 10 \\
\text { Presencia de muro: } 2 \\
\text { Pasarela: } 10\end{array}$ \\
\hline Interpretación & Explicación de los guías: 23 & $\begin{array}{l}\text { Falta de información para llegar al sitio: } 7 \\
\text { Falta de cartelería explicativa en el sitio: } 5\end{array}$ \\
\hline Sin opinión & No Contesta: 5 & --- \\
\hline
\end{tabular}

Tabla 1. Opiniones acerca de la visita, las respuestas son múltiples.

Por su parte, se pudo constatar que los datos que surgen de las entrevistas realizadas al personal que brinda las visitas guiadas y a los encargados del sitio concuerdan con lo relevado en el libro de visitantes, en relación a las épocas de mayor afluencia de turistas y sobre la procedencia de los mismos. En las entrevistas señalan que los contingentes provienen de la misma provincia, principalmente de la capital o de Merlo y que, entre los meses de septiembre y octubre, asiste el público escolar y también turistas extranjeros. Algo interesante que ellos han identificado es el perfil de tres tipos de visitantes: los que se interesan por el turismo cultural, que poseen información y saben qué vienen a ver; los turistas menos informados, pero que esperan ver arte rupestre y los que no saben bien qué fueron a ver. 
Los guías y encargados también mencionan los reclamos que reciben o escuchan de los visitantes. En sintonía con los resultados de las encuestas, se insiste con el desagrado ante la presencia de pasarelas y asfalto hasta la entrada de la cueva, la ausencia de información general y de explicaciones mediante cartelería y otras cuestiones ligadas a los servicios, como es la falta de botiquín de primeros auxilios.

Una integrante de una empresa de turismo local señaló de manera muy explícita las actitudes de los turistas:

Mucha gente que viene, conoce el lugar, sabe que existe, pero no lo identifica como tal, lo confunden con otros lugares del sur, u otros donde hay pinturas, inclusive con la mina, como si todo fuera lo mismo (...). Van con la expectativa de las pinturas y después no ven nada, un hueco (...). A veces hay publicadas imágenes de pinturas que están cerca, pero no ahí. A los de Turismo le decís que no se ven las pinturas y las siguen difundiendo. La gente llega convencida que va a ver pinturas y no hay (...) y encima está la falencia que no hay una actividad organizada diaria.

También afirmó que:

A la gente, más allá de la gruta, que es impactante, le interesa mucho el arte rupestre, en la gruta eso no se puede ver. A la gente también se le explica que Intihuasi no es un pueblo; muchos creen que se van a encontrar con un pueblo, les decimos que es un sitio arqueológico. Entonces la gente lo piensa dos veces, porque la gente comúnmente cuando le decís que no hay pueblo, no hay pinturas, no hay lugares recreacionales, y tiene que hacer $20 \mathrm{~km}$, decide no ir, porque le va a llevar una hora más".

En su discurso también reconoce que:

El que va ahí es porque le interesa la arqueología, el arte rupestre, porque tiene cierto nivel cultural, nosotros lo vendemos como un lugar arqueológico, si les interesa la arqueología y el valor que tiene la gruta van; si no, no (comunicación personal, 2 de Julio de 2019, La Carolina).

En todos los casos se evidencia la falta de información, tanto en las ciudades desde donde se enlazan las visitas a Intihuasi, como en las agencias de turismo y/o en páginas de internet. A ello se suman otros reclamos vinculados con la infraestructura turística y la logística en la zona, tales como la falta de cajeros automáticos y de estaciones de servicio.

\section{Declaración de significación cultural de Intihuasi}

\section{Evaluación de grupos de interés}

Se consideran grupos de interés a aquellas personas, grupos o comunidades que, de alguna manera, están involucrados o son afectados por el sitio. En este caso se entrevistaron a diferentes personas vinculadas a Intihuasi y su zona de influencia, las que pueden ser agrupadas en: vecinos del Paraje Intihuasi; pobladores de La Carolina; propietarios de tierras circundantes a la gruta; emprendedores turísticos y hoteleros; guías locales independientes; empleados del Museo de la Poesía y Complejo Cultural Provincial Lafinur; dueños de museo privado; autoridades de diferentes niveles de gobierno; pueblos originarios; investigadores y otros especialistas; comunidad 
educativa (docentes y alumnos); visitantes al sitio; organizaciones no gubernamentales interesadas en el patrimonio.

\section{Significación social de Intihuasi}

A partir de los testimonios recogidos se pudieron identificar los valores con los cuales los grupos de interés asocian al sitio.

\section{A) Valor científico}

Este valor es fuertemente señalado por investigadores y especialistas ${ }^{8}$ quienes son los que cuentan con más información sobre el contexto histórico, cultural y científico. Esta alta valoración se puede asociar principalmente a dos disciplinas: la arqueología y la geología. En el primero de los casos, se debe a que Intihuasi es un sitio arqueológico que evidencia una ocupación humana constante en los últimos ocho mil años. A ello se suma su importancia para la historia de la arqueología, porque fue donde se aplicó por primera vez la técnica del fechado radiocarbónico en Sudamérica realizado por el prestigioso arqueólogo Alberto Rex González, quien estuvo además a cargo de su excavación y estudio. Ambas cuestiones se potenciaron. De hecho, al tratarse del primer sitio fechado del país, durante mucho tiempo la gruta estuvo considerada como uno de los sitios más tempranos, hasta que se incrementaron las dataciones que ampliaron el rango temporal de la ocupación humana.

En el aspecto geológico se destaca su valor como paisaje volcánico, así como la presencia de minerales que han sido objeto de explotación constante desde la época colonial. En este punto el Dr. Ariel Ortiz Suárez destaca:

La gruta de Intihuasi se emplaza en un cerro de origen volcánico que forma parte de un cinturón eruptivo. Dicho cinturón se encuentra entre La Carolina y El Morro (ambos en la provincia de San Luis), y se ha originado entre los diez y dos millones de años, aproximadamente, como producto de los procesos geológicos que han dado lugar a la cordillera de los Andes y a partir de una situación singular ocurrida entre los $28^{\circ}$ y $32^{\circ}$ de latitud Sur (comunicación personal, 1 de Julio de 2019, San Luis).

Una cuestión que merece ser estudiada con mayor profundidad es el posible valor arqueoastronómico de la gruta. Algunos testimonios afirman que el 21 de diciembre entra el sol e ilumina la cueva por completo. Esto podría explicar su denominación con los vocablos quechua Inti Huasi, que significa casa del sol y proveer una razón adicional para su ocupación recurrente por parte de grupos nativos, así como su uso ritual. Todas estas hipótesis merecen ser corroboradas con estudios de astronomía cultural.

\section{B) Valor histórico}

La gruta fue escenario de diferentes sucesos que, aunque no son muy conocidos, permiten otorgarle a la misma un valor histórico significativo; entre ellos se destacan dos en particular. El primero fue la firma de la ratificación de la Independencia Nacional el 2 de septiembre de 1816. La ceremonia se realizó en Intihuasi, fue presidida por el Alcalde de Hermandad, Don Juan Gregorio Lucero y firmaron el acta Juan Alejandro Sosa, Paulino Ortiz, Juan Miguel de Guaicoechea, Francisco M. Lucero, Domingo Sosa y Francisco Funes (conforme consta en el Archivo Histórico de San Luis, Carpeta N- 20

8 Se entrevistaron a especialistas de distintas disciplinas (arquitectura, historia, arqueología, geología y turismo), a aficionados y gestores culturales. 
documento 2492 citado por Tobares, 1996, p. 41). Al respecto el Gobernador Alberto Rodríguez Saá recientemente ha señalado:

En San Luis, el documento de juramento de la independencia dice que los puntanos la juraron en Intihuasi, no sé si fue en el pueblo o en la gruta, yo creo, lo sueño -y esto ya tiene valor de leyenda- que fue en la gruta y ese es el enorme valor (A. Rodríguez Saá, discurso pronunciado en Intihuasi, 3 de Julio de 2019).

El segundo hito histórico fue que en 1864 Intihuasi fue asiento de una posta en la ruta que iba de San Luis a Villa de Dolores (actual Concarán) pasando por El Trapiche, Laguna Larga, Santa Bárbara, Los Alanices, etc. Las postas más cercanas eran Paso del Rey a cuatro leguas al sur y Agua Blanca a cinco leguas al norte. El maestro de posta en Intihuasi era Don Remicio Rivero (Archivo Histórico de San Luis, Carpeta N166 documento 18.441 citado por Tobares, 1996, p. 41).

Otros dos aspectos son importantes de destacar, el primero de los cuales le otorga profundidad histórica. Se trata de la denominación en quechua, que es asociada a una versión que estima que al sitio lo explotaron los incas, aunque no se encontraron evidencias al respecto, según comenta Ariel Ortiz Suárez. Y agrega, "hay nombres quechuas en la zona, como Tomolasta, Pancanta, debido quizás a que gente de Bolivia y Perú vino para trabajar en la minería en el siglo XVIII y ellos pueden haber usado esos nombres" (A. O. Suárez, comunicación personal, 1 de Julio de 2019, San Luis). Otro vecino sostiene que los españoles pusieron nombres quechuas porque estaban familiarizados con ese idioma, que era la única lengua nativa que hablaban (comunicación personal, 2 de Julio de 2019, La Carolina). Una señora muestra conanas y manos de mortero indígenas que están en el museo privado El Cóndor y afirma que con ellos los indígenas lavaban oro en la zona, como lo hacía su familia y ella misma, que desciende de chilenos que vinieron a trabajar a la mina (comunicación personal, 2 de Julio de 2019, La Carolina).

El otro aspecto es la importancia que la gente le otorga a las excavaciones de Alberto Rex González, realizadas en la década del cincuenta, ya que su estancia y el trabajo efectuado durante un par de meses con peones de la zona, han quedado grabados en la memoria histórica local y se reproducen de boca en boca. De hecho, la interpretación actual de la gruta recrea la excavación de este arqueólogo. En ese sentido, un funcionario provincial del Área de Cultura menciona:

Para la gente de la zona, Intihuasi está muy presente, los niños saben generalidades de Intihuasi, hay una historia oral permanente. Sobre todo, esto de cuando vino Rex González, los niños manejan su nombre como si fuera el tío, el abuelo, el vecino que fue e hizo algo. Rex vino por unos días y se instaló meses en una tapera que le dan los Lucero, compartía asados y trabajaba con gente de ahí, no sé si le pagaría. Los niños de la escuela de Intihuasi dicen que vino un señor y comía asado con mi abuelito y con mi papá que era chiquito. Y cómo se llamaba, no sé; una vez uno me dijo "tiranosaurio" ipor Rex! (...). El suceso de Rex González atraviesa a Intihuasi y es lo único; la gente no sabe qué pasó antes ni después de Rex González, la gruta es Rex González. De hecho, los banners que había en la gruta contaban todo lo de Rex González. No hay nada más (comunicación personal, 1 de Julio de 2019, San Luis).

\section{C) Valor social}

Conforme a diversas entrevistas realizadas en Intihuasi y sus alrededores, la gruta está instalada en la comunidad como un lugar donde se realizaban hasta los años setenta, 
diversos eventos sociales, recreativos, familiares y culturales. Entre los testimonios recogidos, se destacan:

En Intihuasi se hacían fiestas, bailes, carreras cuadreras. Había una comisión de Intihuasi para la escuela y organizaban la fiesta. Se hacían en verano, también se hacían cumpleaños, gente grande de la zona hacía cumpleaños. Todos llegaban a caballo, jhermosa la cabalgata! (vecino de la localidad La Carolina, comunicación personal, 2 de Julio de 2019).

Otro vecino consultado sobre las fiestas, comentó: "Sí, se usaba como una cuestión así, para fiesta, acorde al tamaño, se hacían carreras cuadreras" ${ }^{9}$ la cantina, el baile de acordeón de guitarra, bien tradicional, bien gauchesca" (comunicación personal, 2 de Julio de 2019, La Carolina).

Una guía señala que:

En la gruta, antes de que fuera declarada sitio de interés cultural que uno debe cuidar y proteger, se hacían bailes, se hacían ahí porque era el lugar más grande de la zona, era un salón de fiestas al aire libre, fresquito en verano. Es más, la gruta esa chiquita que está al costado, era donde se hacían las cantinas. Me parece que todavía están unos ganchos que era donde se colgaban los soles de noches para iluminarse y hacer la fiesta. Mi papá y mi abuelo son de Intihuasi y ellos cuentan que era parte de la tradición hacer las fiestas en la gruta (comunicación personal, 2 de Julio de 2019, La Carolina).

Asimismo, una de las pobladoras más antiguas del lugar cuenta con detalle los bailes:

De las mejores fiestas que hubo, se juntaba toda la gente (...), a la cueva le arreglaron el piso con portland y en una esquina hacían los asados y en la otra esquina -según como fuera el viento porque si venía del Sur lo hacían para ese lado, así el humo no entraba a la cueva- tenían donde vendían la bebida. Y adentro estaba nada más para bailar porque no había donde sentarse, porque toda la pared era húmeda y estaban esos verdecitos tan bonitos, que toda la vida hubo "cata", catita, cotorras (...) de esto hace 60 años atrás.

Luego agrega:

Venían músicos, acordeonistas, la gente muy alegre y muy buena, le convidaba comida al que estaba, nos saludábamos todos. Tenían faroles a mercurio, piedras de carburo, lamparitas que entraban a la mina, faroles de kerosene y cuando pasaron los años, faroles a gas. Ha sido muy de fiestas toda la zona. Adolfo Lucero es de esta zona, un señor mayor que seguro recuerda las fiestas. Se escuchaba folklore, tonada, se bailaba cueca, gato, ranchera, pasodoble, hasta tango, hemos bailado, tango sencillo, con pasos tan lindos.

Respecto de la comida, también realiza una detallada descripción:

Asado lo que más se comía, mucha gente en un comité, había una olla muy grande donde se hacía puchero, con arroz, fideos. El vino nunca faltaba, para las mujeres el vino dulce. De postre, había lo que hacíamos en casa de fruta o sino con leche, con huevo, cosas caseras. 
En relación al horario de los encuentros, aclaró: "Un baile de campo empezaba a la hora que se podía ir, a la tarde tocaban la guitarra, jugaban a la taba (...). Era todo el día y a la noche, los que vivíamos lejos nos volvíamos antes" (pobladora de La Carolina, comunicación personal, 2 de Julio de 2019).

Otra vecina aporta sus propios recuerdos sobre las celebraciones en Intihuasi y comenta:

Eran unas fiestas fantásticas, había muchísima gente, guitarreadas. Se ingresaba por un puente porque había un arroyito e íbamos a caballo (...). Las fiestas eran organizadas por la familia, con almuerzos a la canasta y una vez se juntaron todos los primos Lucero, pero luego no pudo volver a hacerse porque ya era de la provincia (comunicación personal, 3 de Julio de 2019, Intihuasi).

A partir de las entrevistas realizadas también se pudo identificar que en años más recientes se llevaron a cabo actividades culturales como conciertos de guitarra y actuaciones de un coro.

No menos importante ha sido en la gruta la veneración religiosa. En ese sentido, un funcionario comenta:

El día en que los niños toman la comunión, van a hacer una pequeña ceremonia en la gruta, se toman fotografías y luego cruzan a lo de los Lucero donde el padre da la misa. Los Lucero son muy devotos y llevan los santos hasta la gruta y organizan todo (comunicación personal, 1 de Julio de 2019, San Luis).

Fabián Romero, quien fue guía freelance en Intihuasi en los años noventa recuerda que:

La patrona de Intihuasi es la Virgen de Lourdes, el 11 de febrero. Para no romper la tradición puse una virgen, era mi compañera, yo pasaba noches solo en la carpa (...) porque el lugareño es creyente ferviente y antes ponían santos y vírgenes en la gruta (comunicación personal, 3 de Julio de 2019, Intihuasi).

También hay que destacar que existe cierto reconocimiento social indígena de la cueva. En efecto, una empleada de la gruta recuerda que: "En Intihuasi una vez se hizo una ceremonia indígena hace dos años (eran ranqueles) y fue por iniciativa propia" (comunicación personal, 20 de Febrero de 2019, Intihuasi). Por su parte, Pascuala Carrizo Guakinchay, integrante del pueblo Huarpe, "Ese lugar tiene mucha energía" (comunicación personal, 21 de Febrero de 2019, San Luis).

\section{D) Valor de paisaje natural}

La gruta de Intihuasi conforma un paisaje, junto con La Carolina y áreas aledañas, de un alto valor desde el punto de vista del patrimonio natural porque muestra las sierras de San Luis con sus pampas de altura, protegiendo ambientes rocosos donde se encuentran yacimientos arqueológicos de importancia. Desde el punto de vista biótico posee especies endémicas de las sierras de Córdoba y de San Luis tales como el sapo serrano (Bufo achalensis) y algunas plantas vasculares (Del Vitto, Petenatti, Nellar y Pettenatti, 1994). Por ello, estos autores proponen proteger el área como una posible reserva natural.

En relación con las especies animales, la gente de la zona manifiesta que en Intihuasi hay cóndores, águila mora, halcón peregrino, puma, zorro y vizcacha.

El valor paisajístico también fue destacado por otros entrevistados. Un guía de trekking que ha recorrido todos los cerros de la provincia menciona que "Intihuasi es el punto 
paisajístico más importante y uno de los cerros más lindos y más altos". Cuando se le consulta sobre los lugares más bellos de la provincia no duda en señalar "el Cerro Sololosta, Casa Pintada y toda la zona de La Carolina e Intihuasi ya que son lugares increíbles, de lo que más me gustan, cerros de origen volcánico" (comunicación personal, 18 de Febrero de 2019, San Luis).

De manera coincidente un arquitecto puntano manifiesta:

Es un lugar muy bello el valle de Pancanta. Casi todos los ríos nacen en esa cuenca, es el corazón del territorio puntano. La gruta debería ser como un templo, para mirarlo con mayor amor (...) en algún momento dado el sol penetra (comunicación personal, 1 de Julio de 2019, San Luis).

\section{E) Valor identitario}

Intihuasi estuvo habitada desde épocas remotas, y las evidencias de esa ocupación le otorgan continuidad a la presencia humana en la zona y aportan profundidad a la identidad puntana.

En todas las entrevistas realizadas a diferentes profesionales (e.g. historiadores, arquitectos, geólogos), así como a gestores de patrimonio, guías de turismo, funcionarios, vecinos, etc., existe coincidencia en señalar la importancia de Intihuasi en el repertorio patrimonial provincial y local. Este valor fue asimismo puesto de manifiesto en el discurso del Gobernador Alberto Rodríguez Saá durante su visita a la gruta el 3 de julio de 2019, donde señaló que "Intihuasi entra en la conversación de los puntanos siempre (...)". Y luego agregó que el lugar tiene "un enorme valor cultural y hace a la puntanidad y al alma de San Luis".

\section{F) Valor político}

Este valor es asignado por acciones de gobierno orientadas a proteger el bien. Al respecto, existen normas legales, tales como la Ley de Yacimientos Paleontológicos y Arqueológicos No II-0062-2004 (5.740) que incluye a Intihuasi entre los sitios con arte rupestre declarados de interés científico. En este punto también se destaca la creación de áreas de gobierno encargadas de su gestión, como es actualmente la Jefatura de Área del Centro Cultural Juan Crisóstomo Lafinur, dentro del organigrama del Programa Cultura, que cuenta entre sus proyectos de trabajo con la planificación de actividades a realizarse en la gruta. Estos aspectos dan muestra de un valor político en ascenso.

\section{G) Valor turístico}

La cueva y su entorno poseen un alto valor turístico, según lo indican las opiniones de algunos visitantes que fueron encuestados al azar. Todos resaltan la belleza de la gruta y del paisaje y su importancia histórica. Los guías y las personas relacionados con las agencias de viaje y promoción turística consideran que tiene aún un potencial poco explotado. La idea de integrar la gruta a diferentes itinerarios turísticos es un tema recurrente. Así, por ejemplo, la arquitecta Pilar Olivera Aguirre considera que:

Habría que armar un circuito con las pinturas rupestres, el tema es el deterioro. Yo haría una huella desde La Carolina, pasas por Intihuasi, dar toda la vuelta al Tomolasta que es el cerro, llegar a Paso del Rey y en ese camino cruzar ríos y pequeños lugares donde hay pinturas rupestres (comunicación personal, 19 de Febrero de 2019, San Luis). 
Por otra parte, en su discurso de bienvenida en Intihuasi durante la visita del gobernador a la gruta en julio de 2019, Fabián Romero señaló que la puesta en valor de Intihuasi "va a generar trabajo para la zona", poniendo de manifiesto una expectativa generalizada en la región.

\section{H) Valor educativo}

Este es un lugar de referencia para el ámbito educativo. Propuestas de aprendizaje y enseñanza, vinculadas además con el turismo, son ofrecidas por operadores turísticos -como Huellas - y también por parte de grupos Intercolegiales Culturales del Programa Cultura de la provincia. Precisamente el día 3 de julio, previamente a la visita del gobernador, alumnos de las escuelas de la zona fueron invitados a concurrir con sus docentes para visitar la gruta y desarrollar actividades educativas y recreativas en la sala de exhibición de la confitería, donde se efectuó un juego de preguntas y respuestas, conocido como "preguntados", sobre la geografía e historia de San Luis.

Asimismo, algunos adultos que viven en la zona recuerdan que en su niñez eran llevados desde la escuela a conocer la cueva y suelen comentar sobre la existencia de otros sitios con pinturas rupestres en la zona.

\section{Discusión}

Como puede observarse, el sitio Gruta de Intihuasi posee una diversidad de valores asociados que fueron identificados por los diversos grupos de interés consultados. A primera vista no parecen observarse aspectos que generen controversias. Sin embargo, se analizaron diferentes cuestiones que pueden ser fuente de potenciales conflictos a tener en cuenta en la planificación de la gestión cultural del mismo. Así se pudo constatar que uno de ellos es el grado de involucramiento de los pobladores locales en cuestiones comunitarias.

La población, tanto de La Carolina como del Paraje de Intihuasi es caracterizada como no conflictiva. El único episodio que provocó la movilización de los vecinos de La Carolina fue cuando se supo de exploraciones de empresas mineras multinacionales que redescubrieron oro en la zona. Con la cuestión ambiental en juego, la eventual explotación aurífera hizo reaccionar a los vecinos. Este tema no es menor porque también se ha hallado oro en las inmediaciones de la gruta. No obstante, existe una normativa legal en San Luis que prohíbe el uso de químicos que afecten el ambiente en la minería provincial y se fomenta la minería tradicional, de tipo manual. De modo que el riesgo de impacto ambiental, social y cultural de la minera industrial estaría acotado, al igual que los potenciales conflictos que eventualmente genere.

En contraste, se ha señalado que la gente local sabe poco acerca del valor científico y cultural de Intihuasi y, en el caso de los habitantes de La Carolina, no la sienten como propia. Como se ha mencionado anteriormente, en la década del noventa carecía de protección y su uso era incompatible desde el punto de vista de la conservación del lugar.

Otra cuestión que se indagó fue la posible vinculación del sitio con los pueblos indígenas. Hasta el momento, no se ha identificado ninguna clase de interés manifiesto o reclamo sobre su pertenencia por parte de indígenas, representantes o grupos de comunidades originarias (i.e. Huarpes, Ranqueles). No menos relevante es la cuestión de las colecciones de Intihuasi provenientes de la excavación de Alberto Rex González, ya que la mayor parte se encuentra fuera de la provincia (i.e. Museo de Ciencias Naturales de La Plata y Museo de Antropología de Córdoba). Si bien no ha habido 
reclamos, ello se debe en gran parte al desconocimiento de su existencia. La carencia de un repositorio oficial en la provincia de San Luis que sea adecuado para la guarda de colecciones arqueológicas también ha contribuido a que no se notara su falta. Esto podría estar vinculado también a que las investigaciones arqueológicas sistemáticas en la provincia no tienen muchos años de haberse iniciado y, por lo tanto, este no ha sido un tema en la agenda de los organismos encargados de su protección.

Probablemente hay otras dos cuestiones con mayor potencialidad para generar conflictos futuros: por un lado, la propiedad de las tierras circundantes y por otro, aspectos vinculados a los diferentes niveles de gobierno. En relación a la primera, la familia Lucero posee tierras en los alrededores de la gruta. Julio César Lucero administra una pequeña hostería y planea continuar edificando cabañas y demás infraestructura turística. Su propiedad actual y las proyectadas se encuentran en la zona circundante a la gruta y en su área de amortiguación visual, por lo que su proyecto podría entrar en conflicto con la preservación y puesta en valor del área. Respecto de la segunda cuestión, la existencia de gobiernos de distinto signo político en la provincia y en la localidad de La Carolina le suma otro ingrediente al manejo del sitio que, si bien es de gestión provincial, no se ve favorecido con la eventual sinergia que podría aportar una mayor coordinación entre diferentes niveles de gobierno. Por el contrario, actualmente existe un proyecto ${ }^{10}$ de un museo municipal en La Carolina en el que se plantea incluir contenidos vinculados con la gruta. De concretarse, este entraría en clara competencia con la interpretación in situ que se ofrecería desde la gestión provincial.

Otro aspecto que se consideró importante para investigar fueron las opiniones en cuanto a lo que debería hacerse para mejorar la presentación del sitio al público. Existen coincidencias, tanto de los entrevistados como de los visitantes encuestados sobre la necesidad de volver la gruta a su estado original (i.e. quitarle el pavimento, las pasarelas, las cuadrículas) e integrarla al paisaje natural, a la vez que mejorar la interpretación del sitio. Estas cuestiones también han sido señaladas por la gestión actual, desde donde se insiste en la necesidad de aumentar el tiempo de estadía en la zona con nuevas actividades, lo que sin duda contribuiría a fortalecer la economía local.

\section{Comentarios finales}

En vista de todo lo expuesto cabe efectuar un balance acerca de cuál sería un futuro posible para Intihuasi. Si bien se trata de un monumento provincial catalogado como sitio con arte rupestre, no posee actualmente pinturas que puedan ser captadas por el ojo humano y su soporte, la gruta, presenta ciertos riesgos estructurales que pueden llegar a desaconsejar el ingreso a su interior por parte de visitantes. A pesar de ello, nuevas excavaciones y la implementación de tecnologías de mayor precisión han permitido reactivar su valoración científica, mediante la identificación de nuevas pinturas en otros sectores del sitio, así como la obtención de fechados recientes que están aportando información inédita. No menos importante es el potencial que Intihuasi ofrece por su valor paisajístico, histórico, cultural y sobre todo turístico, lo cual abre un nuevo abanico de oportunidades. A ello se suma el interés del gobierno provincial en mejorar su puesta en valor, ampliando la protección a toda su área de influencia. En el marco de este panorama que se presenta como alentador, no puede dejar de considerarse que la diversidad de valores e intereses antes mencionada puede llegar a contraponerse o bien simplemente coexistir, sin que se genere una sinergia entre los mismos. Todo ello podría producir desavenencias al momento de poner en valor la gruta.

10 No se dispone de mayores detalles acerca del contenido sobre Intihuasi que se incluiría en el diseño museológico de dicho museo, aunque ello fue mencionado en las entrevistas. 
Este no es un tema menor. Cabe recordar una vez más que el patrimonio cultural es una construcción social, subjetiva y multívoca (Endere, 2009; Gianotti García et al., 2014; Prats, 2004; entre muchos otros), por lo que la emergencia de conflictos no sólo es posible, sino que es altamente probable. Por ello, esta cuestión no puede ser en ningún momento desantendida y mucho menos desestimada en la gestión patrimonial, sobre todo cuando se está trabajando en un sitio que tiene una enorme raigambre en la memoria emotiva de la comunidad. En virtud de ello, se considera que tan importante como poner en valor el sitio, es hacerlo de una manera que propenda a establecer un equilibro entre los valores en juego $y$, de este modo, contribuya a revalorarlo desde el punto de vista social y cultural. Es en este sentido que se espera que el presente estudio promueva el interés por implementar políticas de gestión que promocionen la participación comunitaria de todos los grupos de interés, ya que ello permitirá su sostenibilidad a largo plazo.

\section{Agradecimientos}

A los evaluadores y/o evaluadoras anónimas que con sus comentarios ayudaron a mejorar el manuscrito. A todos aquellos y aquellas que generosamente ofrecieron su tiempo para ser entrevistados, encuestados y/o consultados, así como a funcionarios de la provincia de San Luis por atender a nuestras consultas. Para preservar la identidad de los entrevistados y las entrevistas se opta por no consignar sus nombres, indicando solo su condición y en algunos casos su ocupación. Este trabajo fue realizado en el marco de las investigaciones desarrolladas por PATRIMONIA (Programa Interdisciplinario de Estudios del Patrimonio), INCUAPA (U.E. CONICET - UNICEN), financiado a través del proyecto PICT 0551/16 y financiado por la ANPCyT. 


\section{Q Referencias citadas}

»Ameghino, F. (1885). Informe sobre el Museo Antropológico y Paleontológico de la Universidad Nacional de Córdoba durante el año 1885. Boletín de la Academia Nacional de Ciencias de Córdoba, VIII, 347-360.

»Ave Lallemant, G. (1875). Apuntes sobre la geognosia de la sierra de San Luis. Actas de la Academia Nacional de Ciencias, 1(5), 103-140.

» Avrami, E., Mason, R. y De la Torre, M. (Eds.). (2000). Values and Heritage Conservation. Research Report. Los Angeles: The Getty Conservation Institute.

» Burmeister, H. (1876). Description physique de la République Argentine: D’après des observations personnelles et étrangères. Paris: F. Savey.

» Cabrera, P. (1929). Los Aborígenes del País de Cuyo. Revista de la Universidad Nacional de Córdoba, s/n, 25-28.

» Consens, M. (1986). San Luis. El Arte Rupestre de sus Sierras. San Luis: Dirección Provincial de Cultura.

» Curtoni, R. y Heider, G. (2019). La Gruta de Intihuasi y su relevancia en la Arqueología Argentina. Informe I. Convenio Universidad Nacional del Centro de la Provincia de Buenos Aires y Universidad Nacional de San Luis, San Luis. Manuscrito inédito.

» Curtoni, R., Oliván, A., Heider, G., Borgo, M., Martínez, V. y Dupuy, P. (2019). Identificación de Arte Rupestre en la Gruta Intihuasi. Plan y Protocolo de Manejo de la "Gruta de Intihuasi". Informe III. Convenio Universidad Nacional del Centro de la Provincia de Buenos Aires y Universidad Nacional de San Luis, San Luis. Manuscrito inédito.

»De Aparicio, F. (1926-1928). Investigaciones arqueológicas en la región serrana de la provincia de San Luis. En Actas del XXII Congreso Internacional de Americanistas, Tomo I (pp. 453-466). Roma, Italia

» De la Torre, M. (2002). Assessing values in cultural heritage. Los Angeles: The Getty Conservation Institute.

» Del Vitto, L., Petenatti, E., Nellar, M. y Pettenatti, M. (1994). Las áreas naturales protegidas de San Luis, Argentina. Multequina, 3, 141-156.

»Endere, M. (2009). Algunas Reflexiones acerca del Patrimonio. En M. Endere y J. Prado (Eds.), Patrimonio, Ciencia y Comunidad. Su abordaje en los Partidos de Azul, Tandil y Olavarría (pp. 17-45). Olavarría: Combessies.

»Endere, M., Chaparro, M. y Giacomasso, V. (2019). Lineamientos Generales para un Protocolo y Plan de Manejo de la Gruta Intihuasi (Provincia de San Luis). Plan y Protocolo de Manejo de la "Gruta de Intihuasi". Informe III. Convenio Universidad Nacional del Centro de la Provincia de Buenos Aires y Universidad Nacional de San Luis, San Luis. Manuscrito inédito.

» Endere, M., Chaparro, M., Bonnin, M., Pupio, A., Otero, A., Cantar, N., Mariano, C., Conforti, M., Giacomasso, V. y Mariano, M. (2018). Conclusiones del "Simposio Internacional de Patrimonio Cultural y Comunidad Local. Buenas prácticas de gestión" (SIPCom). Revista del Museo de Antropología, 11(2), 123-126. https://doi.org/10.31048/1852.4826.v11.n2.20946

» Endere, M. y Prado, J. (2009). Criterios de selección valorización y zonificación de yacimientos arqueológicos y paleontológicos. En M. Endere y J. Prado (Eds.), Patrimonio, Ciencia y Comunidad. Su abordaje en los Partidos de Azul, Tandil y Olavarría (pp. 49-66). Olavarría: Combessies.

»Fernández, J. (1982). Historia de la Arqueología Argentina. Mendoza: Asociación Cuyana de Antropología.

"Ferrari, A. (1993). Introducción a la obra científica y técnica de Germán Avé-Lallemant en la República Argentina (ca. 1835-1910). Buenos Aires: Instituto Científico y Cultural El Diario. 
» Feilden, B. y Jokilehto, J. (1993). Management Guidelines for World Cultural Heritage Sites. Roma: ICCROM.

» Funes, M. (2006). Carolina un paisaje de mineros. (Tesis de Licenciatura inédita), Universidad de Buenos Aires, Argentina.

» García Blanco, A. (1999). La exposición, un medio de comunicación. Madrid: Akal.

» Gez, J. ([1916]1986). La Historia de la provincia de San Luis. San Luis: Comisión Nacional del Centenario de la Independencia Argentina y San Luis Libros.

» Giacomasso, V. y Endere, M. (2019). La Legislación Patrimonial de la Provincia de San Luis. Consideraciones sobre cuestiones vinculadas con la identidad, la participación y la sustentabilidad sociocultural. Comechingonia, Revista de Arqueología, 23(2), 199-218. https:// doi.org/10.37603/2250.7728.v23.n2.27495

» Gianotti García, C., Barreiro Martínez, D. y Vienni Baptista, B (Coord.). (2014). Patrimonio y Multivocalidad. Teoría, práctica y experiencias en torno a la construcción del conocimiento en Patrimonio. Montevideo: CSIC Biblioteca Plural y Universidad de la República de Uruguay.

» González, A. R. (1960). La estratigrafía de la gruta de Intihuasi (Prov. de San Luis, R. A.) y sus relaciones con otros sitios precerámicos de Sudamérica. Revista del Instituto de Antropología, 1, 5-296.

» Grenville, J. y Fairclough, G. (2004). Characterisation. Introduction. Conservation Bulletin, 47, 2-3.

» Greslebin, H. (1928). La Antigüedad del hombre en la región de Sayape, Provincia de San Luis, República Argentina. Nota preliminar. En Proceedings of the Twenty-third International Congress of Americanists (pp. 305-312). Nueva York.

» Heider, G. y Curtoni, R. (2016). Investigaciones arqueológicas en la Provincia de San Luis: a 150 años de sus inicios, historia y perspectivas. Revista del Museo de Antropología, 9(1), 3548. https://doi.org/10.31048/1852.4826.v9.n1.12902

»ICOMOS. (1964). Carta de Venecia sobre conservación y restauración de sitios y monumentos, https://www.icomos.org/charters/venice_sp.pdf (Acceso: 10 de febrero, 2020).

» ICOMOS, Australia. (1979) Carta de Burra para Sitios de significación Cultural. ICOMOS Australia, Burra, 1988 y modificada en 1999, https://australia.icomos.org/publications/burracharter-practice-notes/burra-charter-review-process (Acceso: 10 de febrero, 2020).

» Larsen, K. (Ed.). (1995). Nara Conference on Authenticity. Proceeding UNESCO World Heritage Centre, Agency for Cultural Affairs (Japan), 1-6 November 1994. Tokio: International Centre for the Study of the Preservation and Restoration of Cultural Property, International Council on Monuments and Sites.

» Lipe, W. (1990). Value and meaning in cultural resources. En H. Cleere (Ed.), Approaches to the Archaeological Heritage. A Comparative Study of World Cultural Resource Management Systems (pp. 1-11). Cambridge: Cambridge University Press.

» Montes, A. (1955). El Ministerio de la Cordillera de los Apóstoles. Revista San Luis, 30, 46-48.

»Outes, F. (1926). Algunos apuntes sobre la arqueología de la provincia de San Luis. Physis, 8, 275-304.

»Prats, L. (2004). Antropología y Patrimonio. Barcelona: Ariel.

»Pérez Gutiérrez de Sánchez Vacca, S. (1998). Las postas del camino real en San Luis. Relatos de viajeros. San Luis: Fondo Editorial Sanluiseño.

»Pérez Santos, E. (2000). Estudios de visitantes en museos. Metodología y aplicaciones. Madrid: Trea.

» Taylor, S. y Bogdan, R. (1996). Introducción a los métodos cualitativos de investigación. Buenos Aires: Paidós.

» Tobares, J. (1996). Noticias para la Historia de los Pueblos de San Luis. San Luis: Fondo Editorial Sanluiseño. 
» UNESCO. (2013). Managing Cultural World Heritage, https://whc.unesco.org/en/managingcultural-world-heritage/ (Acceso: 10 de febrero, 2020).

» Vacca, D. y Nuñez, U. (1967). Historia de San Luis. San Luis: Godeva.

» Vignati, M. (1936). Resultados antropológicos de algunos viajes por la provincia de San Luis. Notas del Museo de La Plata, Antropología, 2(1), 309-348.

»Vignati, M. (1937). Apuntes de un viaje por la provincia de San Luis. Revista del Museo de La Plata (Nueva Serie), 53-60.

»Vignati, M. (1941). Culturas Prehispánicas y protohistóricas de la Provincia de San Luis. II: Antecedentes Bibliográficos: Los Modernos. Notas del Museo de La Plata, Antropología, 21(6), 1-26. 